\title{
Short-term decreased physical activity with increased sedentary behaviour causes metabolic derangements and altered body composition: effects in individuals with and without a first-degree relative with type 2 diabetes
}

\author{
Kelly A. Bowden Davies ${ }^{1,2}$ (D) V Victoria S. Sprung ${ }^{1,2} \cdot$ Juliette A. Norman $^{1,2} \cdot$ Andrew Thompson $^{3} \cdot$ Katie L. Mitchell ${ }^{4}$. \\ Jason C. G. Halford ${ }^{4}$. Jo A. Harrold ${ }^{4}$. John P. H. Wilding ${ }^{1,5}$. Graham J. Kemp ${ }^{1,6}$ - Daniel J. Cuthbertson ${ }^{1,2}$
}

Received: 15 November 2017 / Accepted: 2 March 2018 / Published online: 18 April 2018

(C) The Author(s) 2018

\begin{abstract}
Aims/hypothesis Low physical activity levels and sedentary behaviour are associated with obesity, insulin resistance and type 2 diabetes. We investigated the effects of a short-term reduction in physical activity with increased sedentary behaviour on metabolic profiles and body composition, comparing the effects in individuals with first-degree relatives with type 2 diabetes (FDR+ve) vs those without (FDR-ve).

Methods Forty-five habitually active participants (16 FDR+ve [10 female, 6 male] and 29 FDR-ve [18 female, 11 male]; age 36 \pm 14 years) were assessed at baseline, after 14 days of step reduction and 14 days after resuming normal activity. We determined physical activity (using a SenseWear armband), cardiorespiratory fitness $\left(\mathrm{V}_{2 \text { peak }}\right)$, body composition (dual-energy x-ray absorptiometry/magnetic resonance spectroscopy) and multi-organ insulin sensitivity (OGTT) at each time point. Statistical analysis was performed using a two-factor between-groups ANCOVA, with data presented as mean \pm SD or (95\% CI).

Results There were no significant between-group differences in physical activity either at baseline or following step reduction. During the step-reduction phase, average daily step count decreased by 10,285 steps (95\% CI $9389,11,182 ; p<0.001)$, a reduction of $81 \pm 8 \%$, increasing sedentary time by $223 \mathrm{~min} /$ day $(151,295 ; p<0.001)$. Pooling data from both groups, following step reduction there was a significant decrease in whole-body insulin sensitivity (Matsuda index) $(p<0.001)$, muscle insulin sensitivity index $(p<0.001)$, cardiorespiratory fitness $(p=0.002)$ and lower limb lean mass $(p=0.004)$. Further, there was a significant increase in total body fat $(p<0.001)$, liver fat $(p=0.001)$ and LDL-cholesterol $(p=0.013)$, with a borderline significant increase in NEFA AUC during the OGTT $(p=0.050)$. Four significant between-group differences were apparent: following step reduction, FDR+ve participants accumulated $1.5 \%$ more android fat $(0.4,2.6 ; p=0.008)$ and increased triacylglycerol by $0.3 \mathrm{mmol} / 1(0.1,0.6 ; p=0.044)$. After resuming normal activity, FDR+ve participants engaged in lower amounts of vigorous activity $(p=0.006)$ and had lower muscle insulin sensitivity $(p=0.023)$. All other changes were reversed with no significant between-group differences.

Conclusions/interpretation A short-term reduction in physical activity with increased sedentary behaviour leads to a reversible reduction in multi-organ insulin sensitivity and cardiorespiratory fitness, with concomitant increases in central and liver fat and dyslipidaemia. The effects are broadly similar in FDR+ve and FDR-ve individuals. Public health recommendations promoting physical activity should incorporate advice to avoid periods of sedentary behaviour.
\end{abstract}

Kelly A. Bowden Davies

k.bowden-davies@liverpool.ac.uk

1 Musculoskeletal Biology II, Institute of Ageing \& Chronic Disease, University of Liverpool, Liverpool, UK

2 Obesity and Endocrinology Research Group, Clinical Sciences Centre, University Hospital Aintree, Liverpool L9 7AL, UK
Wolfson Centre for Personalised Medicine, Institute of Translational Medicine, University of Liverpool, Liverpool, UK

4 Department of Psychological Sciences, Institute of Psychology Health and Society, University of Liverpool, Liverpool, UK

5 Eye and Vision Science, Institute of Ageing \& Chronic Disease, University of Liverpool, Liverpool, UK

6 Liverpool Magnetic Resonance Imaging Centre (LiMRIC), University of Liverpool, Liverpool, UK 


\section{Research in context}

\section{What is already known about this subject?}

- Low physical activity levels and sedentary behaviour are major risk factors for obesity, the metabolic syndrome and type 2 diabetes

- First-degree relatives of individuals with type 2 diabetes have a threefold higher risk of developing type 2 diabetes compared with those with no family history

What is the key question?

- How does a short-term decrease in physical activity affect metabolic health/body composition and are the associated changes more pronounced in individuals with a first-degree relative with type 2 diabetes vs individuals without?

What are the new findings?

- A reduction in physical activity with increased sedentary behaviour and decreased cardiorespiratory fitness leads to unfavourable changes in body composition with loss of lean mass and accretion of body fat (particularly abdominal and liver fat). Metabolic decompensation was evident, with development of whole-body insulin resistance

- Overall, there was no convincing evidence that the genetic background of type 2 diabetes influences the magnitude of the metabolic derangements or the change in body composition

How might this impact on clinical practice in the foreseeable future?

- These findings emphasise the need for healthcare professionals to educate individuals about the harmful effects of sedentary behaviour/low activity levels and furthermore highlight the importance of a habitually active lifestyle while demonstrating how even subtle changes in physical activity can positively or negatively influence health

Keywords Body composition - Cardiorespiratory fitness · Glucose tolerance $\cdot$ Insulin resistance $\cdot$ Liver fat $\cdot$ Physical activity Sedentary behaviour $\cdot$ Skeletal muscle $\cdot$ Type 2 diabetes

\begin{tabular}{ll}
\multicolumn{2}{l}{ Abbreviations } \\
${ }^{1} \mathrm{H}-\mathrm{MRS}$ & Proton magnetic resonance spectroscopy \\
Adipo-IR & Adipose tissue insulin resistance \\
DBP & Diastolic BP \\
DXA & Dual-energy x-ray absorptiometry \\
FDR+ve & Individuals with a first-degree relative \\
& with type 2 diabetes \\
FDR-ve & Individuals with no first-degree relatives \\
& with type 2 diabetes \\
IHCL & Intrahepatocellular lipid \\
IMCL & Intramyocellular lipid \\
METS & Metabolic equivalents \\
SBP & Systolic BP \\
TEE & Total energy expenditure \\
VIF & Variance inflation factor
\end{tabular}

\section{Introduction}

There is an abundance of epidemiological evidence which indicates that physical inactivity (defined as an insufficient physical activity level to meet physical activity guidelines) and sedentary behaviour (defined as any waking behaviour characterised by an energy expenditure $<1.5$ metabolic equivalents (METS), while in a sitting, reclining or lying posture) are major causal factors in the development of obesity, insulin resistance and type 2 diabetes [1-4]. However, such data provide no mechanistic insight into these pathophysiological changes. One plausible paradigm suggests that a transition to physical inactivity and/or increased sedentary time causes a reduction in skeletal muscle insulin sensitivity, contributing to a repartitioning of energy substrates into storage, increasing central fat accumulation and ectopic storage within the liver and other organs, causing further insulin resistance [5-9]. As peripheral insulin resistance progresses, continued ectopic fat accumulation within the liver and pancreas precipitates development of the metabolic syndrome, a progressive decline in beta cell function and, ultimately, type 2 diabetes [10].

To date, mechanistic studies in humans pertaining to reduced physical activity levels have used extreme experimental models including prolonged bed rest [11], limb immobilisation [12] and cessation of exercise in exercise-trained volunteers [13]. These models are not physiologically representative of habitual activity levels in free-living individuals, and thus should be interpreted cautiously. More recently, an alternative experimental model has been developed in which active ( $\sim 10,000$ steps/day) healthy volunteers, who do not participate in regular exercise, transition to an inactive lifestyle 
(reducing to $\sim 1500$ steps/day) for brief periods ( $\sim 14$ days). This approach reflects societal changes in physical activity levels (i.e. reduced physical activity and more sedentary time) $[14,15]$. Step-reduction models have demonstrated that reduced physical activity results in detrimental physiological changes, including reduced cardiorespiratory fitness, accumulation of central fat, loss of skeletal muscle mass with associated anabolic resistance, and reductions in peripheral insulin sensitivity [16-20]. These changes are reversible with resumption of normal activity in young [18], but not older adults [20]. Importantly, such research provides a mechanistic basis for the consequences of increased sedentary behaviour and aids our understanding of the development of metabolic disease.

First-degree relatives of individuals with type 2 diabetes (FDR+ve) have a threefold increased risk of developing the disease compared with those without a family history (FDR -ve) [21]; this risk can further be increased with low physical activity levels [22]. No previous studies have employed a step-reduction protocol to examine whether individuals genetically predisposed to type 2 diabetes are more susceptible to the adverse metabolic consequences of an inactive lifestyle compared with those who are not. Given that group-specific physical activity guidelines have been proposed for other high-risk groups (e.g. South Asians) and that the exercise dose-response curve clearly differs between populations [23], this is a very pertinent research question. Furthermore, only two studies have investigated whether the detrimental effects of step reduction are reversed when habitual physical activity is resumed: one induced overfeeding during step reduction [18] and the other was conducted in older adults [20].

The primary aim of this study was to investigate the metabolic consequences of short-term decreased physical activity with increased sedentary behaviour in free-living individuals and determine whether more metabolic decompensation is observed in FDR+ve individuals.

\section{Methods}

\section{Participants}

Habitually active participants with no history/current engagement in regular structured exercise ( $>2 \mathrm{~h} /$ week) or highly physical employment (determined by questionnaire) were recruited from local advertisements across hospital departments and university campuses. Exclusions included: cardiovascular, respiratory, kidney, liver and/or endocrine complications, smokers and those consuming $>14$ units/week of alcohol consumption. A first-degree relative was classed as a parent, sibling or child, and participants were divided into two groups: the FDR+ve group included participants with a first-degree relative diagnosed with type 2 diabetes according to medical records; the FDR-ve group included those with no firstdegree relative diagnosed with type 2 diabetes.

The study conformed to the Declaration of Helsinki and was approved by the local research ethics committee (14/ NW/1147 and 14/NW/1145). All participants were informed of the methods verbally and in writing before providing written informed consent prior to any assessments being performed. Prior to each visit, participants were required to fast overnight for $>8 \mathrm{~h}$, abstain from alcohol and caffeine for $24 \mathrm{~h}$ and from exercise for $48 \mathrm{~h}$.

\section{Study design}

Physical activity was assessed in participants' free-living environment. A mean daily step count $>10,000$ was required for participants to be eligible. Screening was blinded and consisted of monitoring from midnight to midnight on 4 consecutive days, including 1 weekend day. If eligible, participants underwent their initial assessment visits before being instructed to reduce their activity to $\sim 1500$ steps for 14 days, after which the assessments were repeated. Habitual activity was then resumed for a further 14 days before participants underwent their final assessment visits (Fig. 1). There were two assessment visits at each time point: (1) at University Hospital Aintree for anthropometry, fasting bloods, OGTT and $\mathrm{V}_{2}$ peak ; and (2) at University of Liverpool for dual-energy x-ray absorptiometry (DXA) and proton magnetic resonance spectroscopy ( $\left.{ }^{1} \mathrm{H}-\mathrm{MRS}\right)$. The study took place between December 2014 and August 2017, and 16 FDR+ve and 29 FDR-ve participants successfully completed the intervention with all measures available (Fig. 2). Dietary records were taken in the 4 days preceding an assessment visit; participants were instructed to maintain their usual dietary habits throughout the study.

\section{Experimental measures}

Anthropometric measurements Weight, height and waist and hip circumferences were measured. Participants then rested for $5 \mathrm{~min}$ before BP was determined from an average of three measures.

Biochemical measurements Blood samples were collected and analysed using the Olympus AU2700 analyser (Beckman Coulter, High Wycombe, UK) with standard proprietary reagents as follows: glucose with hexokinase, total cholesterol and HDL-cholesterol with cholesterol esterase/ oxidase and triacylglycerol with glycerol kinase. LDLcholesterol was calculated according to the Friedewald formula. Insulin was measured using radioimmunoassay (Invitrogen, Paisley, UK). HOMA-IR was calculated using fasting glucose and insulin concentrations [24]. NEFA was measured using a NEFA assay kit (Randox Daytona, County 
Fig. 1 Study design for stepreduction intervention. Complete objective assessment of physical activity throughout screening (baseline), step reduction and resumption of normal activity; $x$ axis represents study day and $y$ axis daily average steps

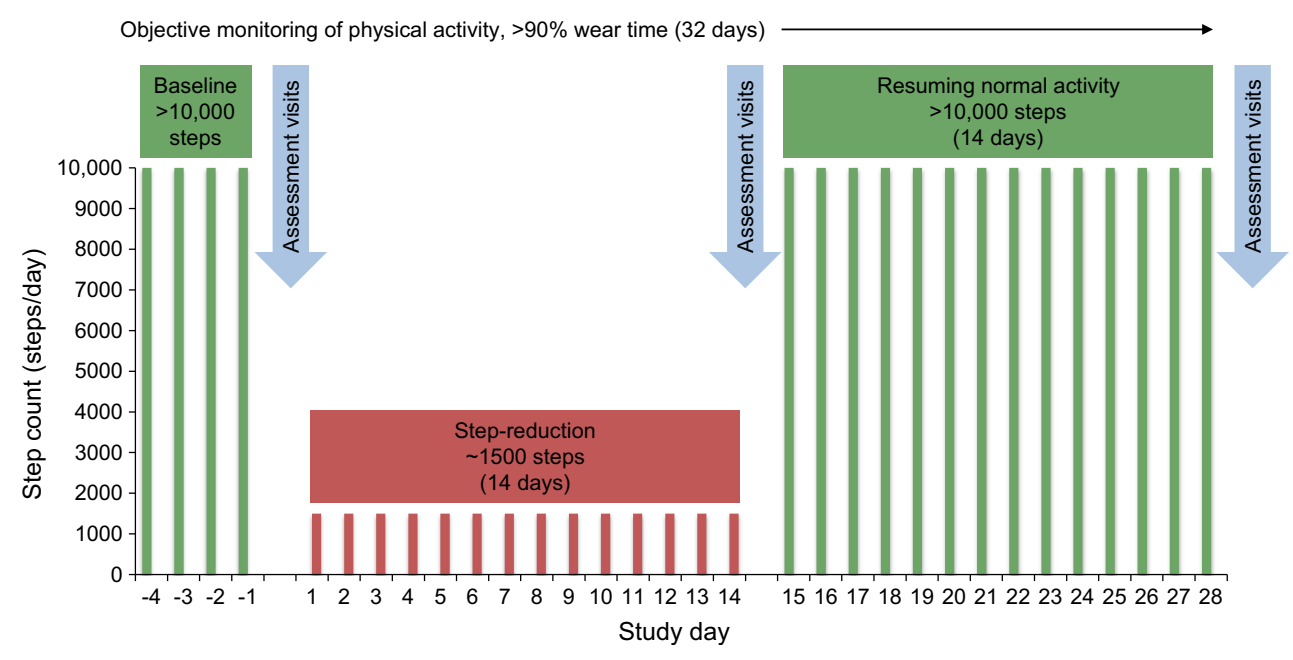

Antrim, UK). Fasting NEFA and insulin concentrations were used to estimate adipose tissue insulin resistance (adipo-IR) [25].

OGTT After fasting blood samples were collected, a $75 \mathrm{~g}$ glucose solution was consumed within $5 \mathrm{~min}$ and post-ingestion blood samples were drawn at 30, 60, 90 and $120 \mathrm{~min}$. Glucose, insulin and NEFA responses were calculated as AUC. Matsuda index was calculated to estimate whole-body insulin sensitivity; indices of hepatic insulin resistance and skeletal muscle insulin sensitivity were determined as previously described [26, 27].

Cardiorespiratory fitness $\mathrm{A} \dot{\mathrm{V}} \mathrm{O}_{2 \text { peak }}$ cardiopulmonary exercise test (CPET) was performed on a treadmill (Model 77OCE, RAM Medisoft Group, Manchester, UK) in a temperaturecontrolled room. The CPET provided breath-by-breath monitoring and analysis of expiratory gases and ventilation as well as continuous electrocardiographic monitoring (Love Medical Cardiopulmonary Diagnostics, Manchester, UK). The modified Bruce protocol was employed: after an initial 2 min warm up at $2.2 \mathrm{~km} / \mathrm{h}$ on a flat gradient, stepwise increments in speed and gradient were employed each min. $\dot{\mathrm{V}} \mathrm{O}_{2 \text { peak }}$ was determined by any of: respiratory exchange ratio $>1.15$; heart rate $>90 \%$ predicted maximum; plateau in $\dot{\mathrm{VO}_{2}}$; or exhaustion. $\dot{\mathrm{V}} \mathrm{O}_{2 \text { peak }}$ data acquired includes: absolute $(1 / \mathrm{min})$, relative to total body mass ( $\mathrm{ml} \mathrm{min}{ }^{-1} \mathrm{~kg}^{-1}$ ), and relative to lean body mass ( $\mathrm{ml} \mathrm{min}{ }^{-1} \mathrm{~kg}^{-1}$; termed ' $\dot{\mathrm{V}}{ }_{2 \text { peak }}$ lean').

Physical activity monitoring Physical activity was tracked throughout using a SenseWear mini armband (BodyMedia, Pittsburgh, PA, USA). Instructions were that the armband was to be worn at all possible times, and the inclusion criterion was $>90 \%$ wear time, which was monitored using SenseWear Professional software (version 8.0). Data collected from the armband included: daily average step count; total energy expenditure; active energy expenditure; and time spent in domains of physical activity, including sleep, lying, sedentary (<1.5 METS), light (1.5-3 METS), moderate (3-6 METS), vigorous (6-9 METS) and very vigorous (>9 METS).

Dietary analysis Total energy consumption, carbohydrate, protein and fat content were determined from dietary records by a registered nutritionist (KLM) using Nutritics (Nutrition Analysis Software for Professionals; https:/www.nutritics. com/p/home; accessed 17 July 2017).
Fig. 2 Screening, recruitment, retention and completion numbers of FDR+ve and FDR-ve individuals in the study

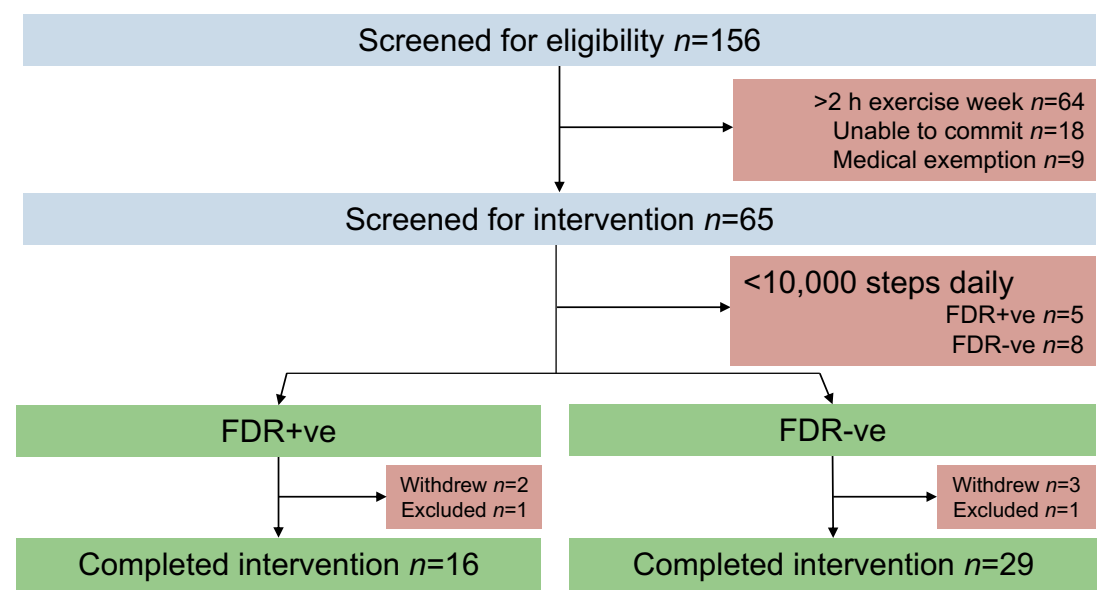


DXA Whole-body scans were performed in line with manufacturer's guidelines using Lunar iDXA (GE Healthcare, Amersham, UK) and were analysed using the instrument's software (version 13.60.033) to determine body fat, lean body mass and bone mineral density. Each scan session was preceded by a calibration routine, using multiple quality-control phantoms that simulate soft tissue and bone.

${ }^{1} \mathrm{H}-\mathrm{MRS}$ Liver and skeletal muscle fat were determined using a 1.5 T Siemens Symphony MRI scanner (Siemens Medical Solutions, Erlangen, Germany) as previously described [28-30]. In brief, intrahepatocellular lipid (IHCL; liver fat) is expressed as the percentage of $\mathrm{CH}_{2}$ lipid signal amplitude relative to water signal amplitude and intramyocellular lipid (IMCL; skeletal muscle fat) is expressed as $\mathrm{CH}_{2}$ lipid amplitude relative to total creatine amplitude.

\section{Sample size calculation}

The primary outcome variable for this study was the difference in insulin sensitivity change between the two groups. Based on previous data [18], using Minitab 16 (https://www. minitab.com/en-us/products/minitab/), a sample size of 50 was calculated to have $\geq 80 \%$ power to detect a standardised mean difference of 0.89 for insulin sensitivity using Matsuda index with 5\% significance level, assuming a 20\% drop-out rate (20 participants per group required).

\section{Statistical analysis}

All data were explored for normality using visual inspection of frequency distribution, and logarithmically transformed where appropriate. Independent $t$ tests were used to determine baseline differences between FDR+ve and FDR-ve individuals. BMI, waist circumference, hip circumference, fasting insulin, HOMA-IR and adipo-IR were significantly different; coefficient of determination $\left(R^{2}\right)$ was calculated from Pearson correlation coefficients to evaluate collinearity between these variables using the variance inflation factor (VIF). BMI had evidence of collinearity with body mass $\left(R^{2}=0.645\right.$; VIF $=$ $2.8)$, waist circumference $\left(R^{2}=0.703\right.$; VIF $\left.=3.4\right)$ and hip circumference $\left(R^{2}=0.719\right.$; $\left.\mathrm{VIF}=3.6\right)$; $\mathrm{BMI}$ was selected as a representative covariate. HOMA-IR had evidence of collinearity with fasting insulin $\left(R^{2}=0.943\right.$; VIF $\left.=17.5\right)$ and adipo-IR $\left(R^{2}=0.639\right.$; VIF $\left.=2.8\right)$; HOMA-IR was selected as a representative covariate. The groups' responses to the intervention were compared by calculating $\Delta$ values and analysed using a two-factor between-groups (group $\times$ time) ANCOVA with respective baseline data, BMI and HOMA-IR values entered as covariates. The term intervention refers to step reduction and resumption of normal activity. Statistically significant interactions were assessed using the least significant difference (LSD) approach to multiple pairwise comparisons, and interactions were used to explore within-group change over time and between-group differences at the specific time points (i.e. step reduction and resumption of normal activity).

We performed sensitivity analysis on significant outcomes using the Bonferroni procedure and found limited variation in variables being adjusted from statistically significant to nonsignificant.

Paired sample $t$ tests were used to assess differences between baseline and resumption of activity because baseline data was entered as a covariate in the ANCOVA models. The $\alpha$ level of statistical significance was set at $p<0.05$. Data are presented as mean \pm SD or $(95 \%$ CI). Data are presented as outcomes for the entire study group (pooled FDR+ ve and FDR-ve); differences between and within groups and changes over time are explicitly noted. Where required, data were logarithmically transformed using $\log _{10}$. Data were back transformed to original units for reporting. Statistical analysis was performed using SPSS for Windows (Version 24.0, SPSS, Chicago, IL, USA).

\section{Results}

\section{Baseline characteristics}

A total of 45 healthy participants ( 28 female, 17 male) were included: 16 FDR+ve (10 female, 6 male) and 29 FDR-ve (18 female, 11 male) (Table 1). The mean age of all the participants was $36 \pm 14$ years, with no statistical difference between the two groups $(p=0.166)$. FDR+ve participants had significantly higher overall body mass, BMI, waist circumference and hip circumference $(p<0.05)$. Fasting insulin, HOMA-IR and adipo-IR were significantly higher in FDR-ve participants. No other variables were statistically different.

\section{Changes in pattern of physical activity}

Mean daily step count was similar between the two groups at baseline: FDR+ve, $12524 \pm 2137$ vs FDR-ve, $13036 \pm 2481$ steps $(p=0.391)$. The intervention induced significant changes in all activity measures (Fig. 3). During the step-reduction period, average daily step count decreased by 10285 steps (95\% CI 9389, 11182; $p<0.001)$, a reduction of $81 \pm 8 \%$. In parallel, daily sedentary time increased by an average of $223 \min (151,295 ; p<0.001)$ and daily total energy expenditure (TEE) decreased by an average of $2697 \mathrm{~kJ}(3008,2385$; $p<0.001$ ). All activity $>1.5$ METS (i.e. light, moderate and vigorous) decreased during the step-reduction period (all $p<0.001$ ). There were no statistical differences between the groups in average daily step count, TEE or sedentary, light or moderate activity at any of the time points $(p>0.05)$. Time spent sleeping was not significantly different between groups and did not change throughout $(p>0.05)$. Vigorous activity 
Table 1 FDR+ve and FDR-ve participant characteristics at baseline

\begin{tabular}{|c|c|c|c|}
\hline Characteristic & $\begin{array}{l}\text { FDR+ve } \\
(n=16)\end{array}$ & $\begin{array}{l}\text { FDR-ve } \\
(n=29)\end{array}$ & $p$ value \\
\hline \multicolumn{4}{|l|}{ Clinical } \\
\hline Age (years) & $40 \pm 14$ & $33 \pm 13$ & 0.166 \\
\hline Body mass (kg) & $79.3 \pm 13.4$ & $68.9 \pm 9.8$ & $0.011^{*}$ \\
\hline BMI $\left(\mathrm{kg} / \mathrm{m}^{2}\right)$ & $27 \pm 5$ & $24 \pm 3$ & $0.018^{*}$ \\
\hline Waist circumference $(\mathrm{cm})^{\mathrm{a}}$ & $93 \pm 13$ & $84 \pm 10$ & $0.029^{*}$ \\
\hline Hip circumference $(\mathrm{cm})^{\mathrm{a}}$ & $103 \pm 11$ & $95 \pm 8$ & $0.015^{*}$ \\
\hline Waist:hip ratio & $0.91 \pm 0.09$ & $0.89 \pm 0.07$ & 0.052 \\
\hline SBP $(\mathrm{mmHg})$ & $122 \pm 14$ & $121 \pm 14$ & 0.932 \\
\hline DBP $(\mathrm{mmHg})$ & $74 \pm 8$ & $76 \pm 10$ & 0.438 \\
\hline \multicolumn{4}{|l|}{ Glucose regulation } \\
\hline Whole-body IS ${ }^{\mathrm{b}}$ & $4.1 \pm 1.9$ & $3.2 \pm 1.9$ & 0.155 \\
\hline Muscle IS index & $0.07 \pm 0.06$ & $0.06 \pm 0.04$ & 0.749 \\
\hline Hepatic IR index & $33.4 \pm 9.7$ & $40.5 \pm 9.4$ & 0.058 \\
\hline NEFA AUC $(\mathrm{mmol} / 1 \times \min )$ & $27 \pm 12$ & $24 \pm 11$ & 0.422 \\
\hline Fasting glucose $(\mathrm{mmol} / \mathrm{l})$ & $5.0 \pm 0.6$ & $5.0 \pm 0.5$ & 0.994 \\
\hline Fasting insulin $(\mathrm{pmol} / \mathrm{l})^{\mathrm{a}}$ & $83 \pm 35$ & $139 \pm 63$ & $0.002^{*}$ \\
\hline HOMA-IR $^{\mathrm{a}}$ & $2.8 \pm 1.1$ & $4.3 \pm 2.1$ & $0.003^{*}$ \\
\hline Adipo-IR ${ }^{\mathrm{a}}$ & $41.6 \pm 26.4$ & $88.2 \pm 55.6$ & $0.004^{*}$ \\
\hline Glucose AUC $(\mathrm{mmol} / 1 \times \mathrm{min})$ & $780 \pm 235$ & $799 \pm 177$ & 0.928 \\
\hline Insulin AUC $(\mathrm{pmol} / 1 \times \mathrm{min})$ & $57368 \pm 27486$ & $63833 \pm 20069$ & 0.468 \\
\hline \multicolumn{4}{|l|}{ Lipid profile } \\
\hline Cholesterol (mmol/l) & $5.1 \pm 1.1$ & $4.9 \pm 0.8$ & 0.681 \\
\hline Triacylglycerol $(\mathrm{mmol} / \mathrm{l})$ & $1.0 \pm 0.5$ & $1.0 \pm 0.6$ & 0.524 \\
\hline HDL-cholesterol (mmol/l) & $1.8 \pm 0.6$ & $1.8 \pm 0.5$ & 0.907 \\
\hline LDL-cholesterol (mmol/l) & $2.8 \pm 1.1$ & $2.6 \pm 0.8$ & 0.475 \\
\hline Cholesterol:HDL-cholesterol ratio & $3 \pm 1$ & $3 \pm 1$ & 0.400 \\
\hline \multicolumn{4}{|l|}{ Body composition } \\
\hline Total body fat $(\%)$ & $33 \pm 10$ & $30 \pm 8$ & 0.279 \\
\hline Android fat $(\%)$ & $36 \pm 12$ & $30 \pm 11$ & 0.134 \\
\hline Gynoid fat $(\%)$ & $35 \pm 11$ & $34 \pm 9$ & 0.581 \\
\hline Total lean mass $(\mathrm{kg})$ & $50.5 \pm 9.1$ & $46.1 \pm 8.9$ & 0.150 \\
\hline Leg lean mass $(\mathrm{kg})$ & $17.5 \pm 3.3$ & $16.0 \pm 3.3$ & 0.164 \\
\hline Arm lean mass (kg) & $5.8 \pm 1.8$ & $5.5 \pm 1.6$ & 0.352 \\
\hline $\operatorname{IHCL}(\%)^{\mathrm{a}}$ & $3.0 \pm 3.6$ & $0.7 \pm 1.0$ & 0.064 \\
\hline $\operatorname{IMCL}(\%)$ & $9.1 \pm 5.0$ & $6.4 \pm 2.6$ & 0.109 \\
\hline \multicolumn{4}{|c|}{ Cardiorespiratory fitness and physical activity } \\
\hline$\dot{\mathrm{VO}} \mathrm{O}_{2}(\mathrm{l} / \mathrm{min})$ & $2.5 \pm 0.4$ & $2.4 \pm 0.6$ & 0.676 \\
\hline$\dot{\mathrm{VO}}_{2 \text { peak }}\left(\mathrm{ml} \mathrm{min}{ }^{-1} \mathrm{~kg}^{-1}\right)$ & $32.1 \pm 6.6$ & $35.3 \pm 6.7$ & 0.136 \\
\hline$\dot{V}_{2 \text { peak }}$ lean $\left(\mathrm{ml} \mathrm{min}^{-1} \mathrm{~kg}^{-1}\right)$ & $50.1 \pm 5.3$ & $52.6 \pm 6.8$ & 0.189 \\
\hline Energy expenditure (kJ/day) & $12251 \pm 2101$ & $11383 \pm 2913$ & 0.408 \\
\hline Daily steps (steps) & $12524 \pm 2137$ & $13036 \pm 2481$ & 0.391 \\
\hline Daily sedentary time (min) & $606 \pm 93$ & $586 \pm 116$ & 0.528 \\
\hline Daily light activity (min) & $231 \pm 78$ & $240 \pm 76$ & 0.650 \\
\hline Daily moderate activity (min) & $130 \pm 41$ & $139 \pm 61$ & 0.306 \\
\hline Daily vigorous activity (min) & $21 \pm 27$ & $24 \pm 31$ & 0.550 \\
\hline
\end{tabular}

Data shown are mean $\pm \mathrm{SD}$ and $p$ values between groups

${ }^{\text {a }}$ Variables analysed following logarithmic transformation

${ }^{\mathrm{b}}$ Matsuda index

${ }^{*} p<0.05$

IR, insulin resistance; IS, insulin sensitivity was significantly higher in FDR-ve participants $(p=0.001)$; when explored, the between-group difference was not present at step reduction $(p=0.988)$ but rather at resumption of activity $(p=0.006)$, with FDR-ve participants increasing their vigorous activity more than FDR+ve participants at this stage (Fig. 3f).

There were no significant differences in any of the physical activity measures between baseline and following resumption of activity, suggesting habitual physical activity levels were successfully restored $(p>0.05)$.

\section{Dietary analysis}

Total energy consumption did not change throughout ( $p=$ 0.330 ) and there was no difference between groups ( $p=$ 0.372 ). Mean \pm SD macronutrient percentages were $56 \pm$ 
a
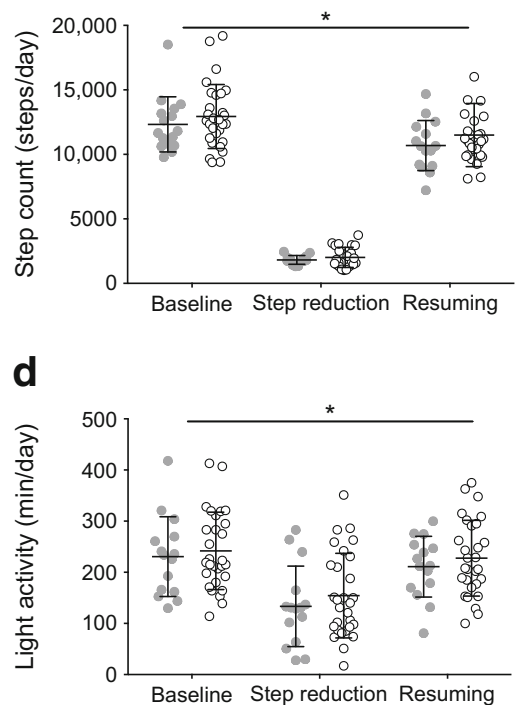

b

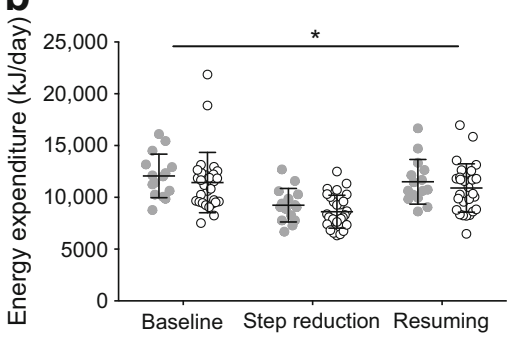

e

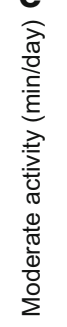

C

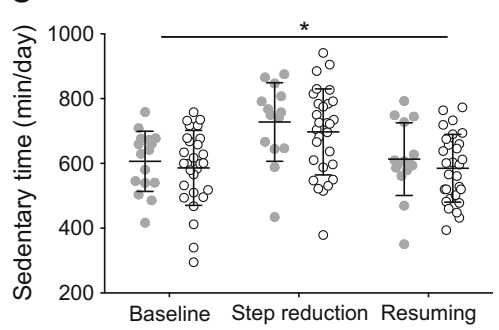

f

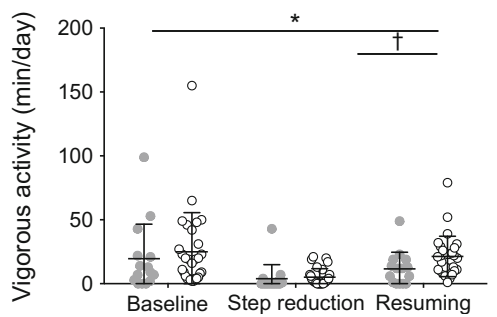

Fig. 3 Physical activity data for FDR+ve and FDR-ve individuals at baseline, following step reduction and resuming activity, including daily average step count (a), TEE (b), daily sedentary time ( $<1.5$ METS) (c), daily light activity (1.5-3 METS) (d), daily moderate activity (3-6
METS) (e) and daily vigorous activity ( $>6$ METS) $(\mathbf{f})$. Data are presented as mean $\pm \mathrm{SD}$. Grey circles, FDR+ve; white circles, FDR-ve. ${ }^{*} p<0.05$ main effect of time; ${ }^{\dagger} p<0.05$ between groups
$15 \%$ carbohydrate, $24 \pm 10 \%$ protein, and $20 \pm 9 \%$ fat, and these did not change throughout $(p=0.235, p=0.268, p=$ 0.924 , respectively) and there was no difference between groups ( $p=0.660, p=0.179, p=0.177$, respectively).

\section{Whole-body insulin sensitivity}

In both groups, the primary outcome measure of whole-body insulin sensitivity (Matsuda index) significantly declined following step reduction $(p<0.001)$, and this was accompanied by a significant increase in glucose AUC $(p=0.025)$ and insulin AUC $(p<0.001)$. However, no between-group differences in these measures were observed (Fig. 4).

\section{Skeletal muscle insulin sensitivity}

Muscle insulin sensitivity was significantly reduced following step reduction $(p<0.001)$. Overall, there was a significant a

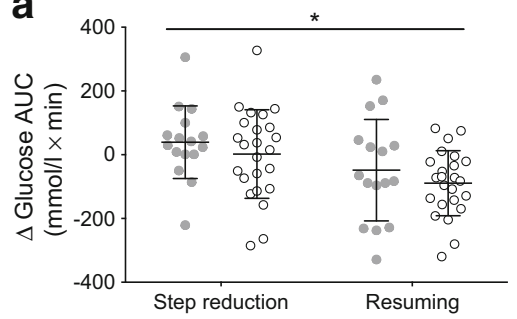

d

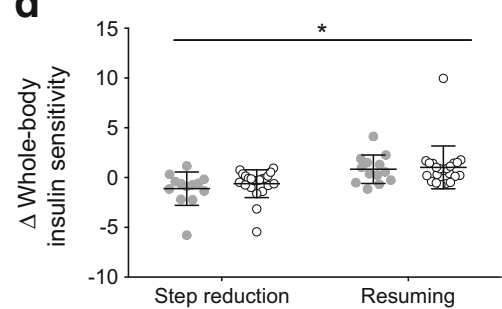

b

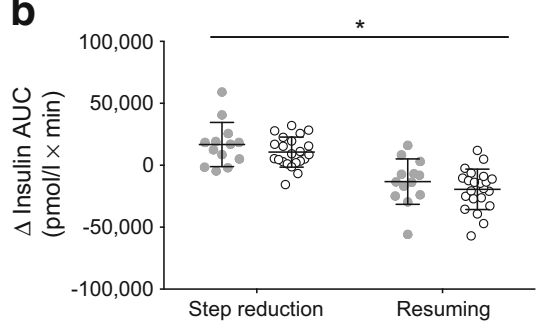

e

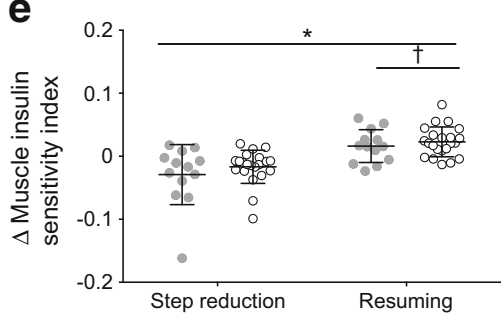

C

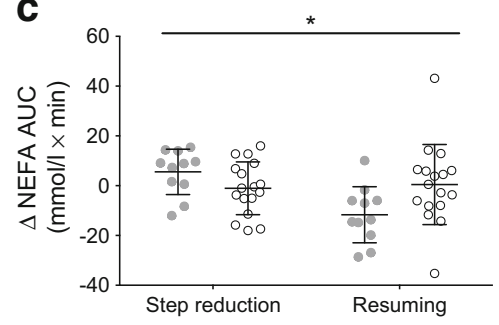

f

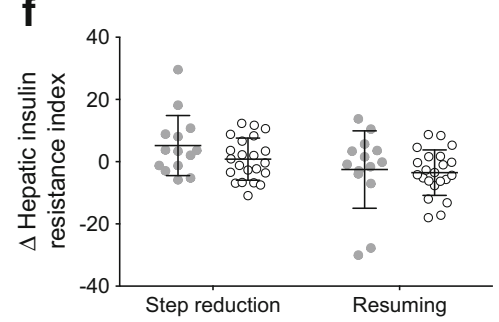

Fig. 4 Metabolic responses of FDR+ve and FDR-ve individuals at baseline, following step reduction and resuming activity. Derived from $2 \mathrm{~h}$ OGTT: glucose AUC (a), insulin AUC (b), NEFA AUC (c), whole-body insulin sensitivity (Matsuda index) (d), muscle insulin sensitivity index (e) and hepatic insulin resistance index (f). Data are presented as mean \pm SD. Grey circles, FDR+ve; white circles, FDR-ve. ${ }^{*} p<0.05$ main effect of time; ${ }^{\dagger} p<0.05$ between groups 
between-group difference of 0.015 (95\% CI 0.006, 0.023; $p=$ 0.001 ), with FDR+ve participants displaying lower levels of muscle insulin sensitivity. Following resumption of activity, there was a significant difference of $0.023(0.003,0.042 ; p=$ 0.023 ) between the two groups, with FDR+ve individuals displaying lower muscle insulin sensitivity (Fig. 4e).

\section{Adipose tissue insulin resistance}

The intervention had a borderline significant effect on NEFA $\operatorname{AUC}(p=0.050$; Fig. 4c).

\section{Hepatic insulin resistance}

The intervention had no significant effect on hepatic insulin resistance in either group ( $p=0.060)$, but hepatic insulin resistance index was, on average, 3.8 greater in FDR+ve individuals across the intervention (95\% CI 1.7, 6.4; $p=0.007$ ) (Fig. 4f).

\section{Clinical characteristics}

Body mass, BMI and waist to hip ratio did not change in either group ( $p=0.611, p=0.553$ and $p=0.385$, respectively). Pooled waist and hip circumference measures increased by $0.7 \mathrm{~cm}(95 \%$ CI $0.4,1.0)$ and $0.4 \mathrm{~cm}(0.1,0.7)$, respectively $(p<0.001)$ after step reduction. Systolic BP (SBP) increased by $4 \mathrm{mmHg}(0,8$; $p=0.037$ ) following step reduction, while diastolic BP (DBP) remained unchanged $(p=0.982)$. There were no between-group differences in any of the changes in clinical characteristic.

\section{Fasting glucose metabolism}

Fasting glucose $(p=0.294)$ and adipo-IR $(p=0.067)$ were not significantly altered by the intervention. Fasting insulin $(p=0.016)$ and HOMA-IR $(p=0.027)$ significantly changed over time.

\section{Lipid profile}

Total cholesterol significantly increased by $0.5 \mathrm{mmol} / 1$ (95\% CI $0.1,0.9 ; p=0.041)$ following step reduction: HDL-cholesterol remained unchanged $(p=0.641)$ while LDL-cholesterol significantly increased by $0.3 \mathrm{mmol} / 1(0.1,0.6 ; p=0.013)$. Triacylglycerol pooled outcomes also increased following step reduction by $0.5 \mathrm{mmol} / \mathrm{l}(0.2,0.7 ; p=0.002)$ but a betweengroup difference was present, with FDR+ve participants having a $0.3 \mathrm{mmol} / \mathrm{l}$ greater change $(0.1,0.6 ; p=0.044)$ (Fig. 4$)$.

\section{Body composition}

Lean body mass Following step reduction, total lean mass decreased by $0.3 \mathrm{~kg}(95 \%$ CI $0.1,0.6 ; p=0.005)$, and lower limb lean mass by $0.2 \mathrm{~kg}(0.1,0.3 ; p=0.004)$, but there was no significant change in arm lean mass $(p=0.502)$.

Regional fat mass Step reduction induced similar changes in both groups: total body fat increased by $0.9 \%$ (95\% CI 0.6, 1.3; $p<0.001$ ) (Fig. 5a), android fat increased by $1.7 \%$ (1.1, 2.3; $p<0.001$ ) (Fig. 5b), and gynoid fat increased by $0.6 \%(0.3$, $0.8 ; p=0.001$ ) (Fig. 5c). A between-group difference was a
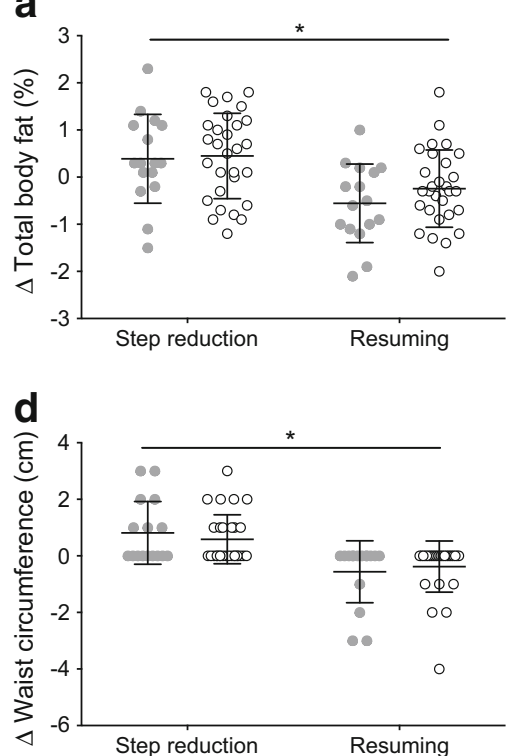

Fig. 5 Responses of FDR+ve and FDR-ve individuals following step reduction and resumption of activity. Change in: (a) total body fat; (b) android (waist) fat; (c) gynoid (hip) fat; (d) waist circumference; (e)
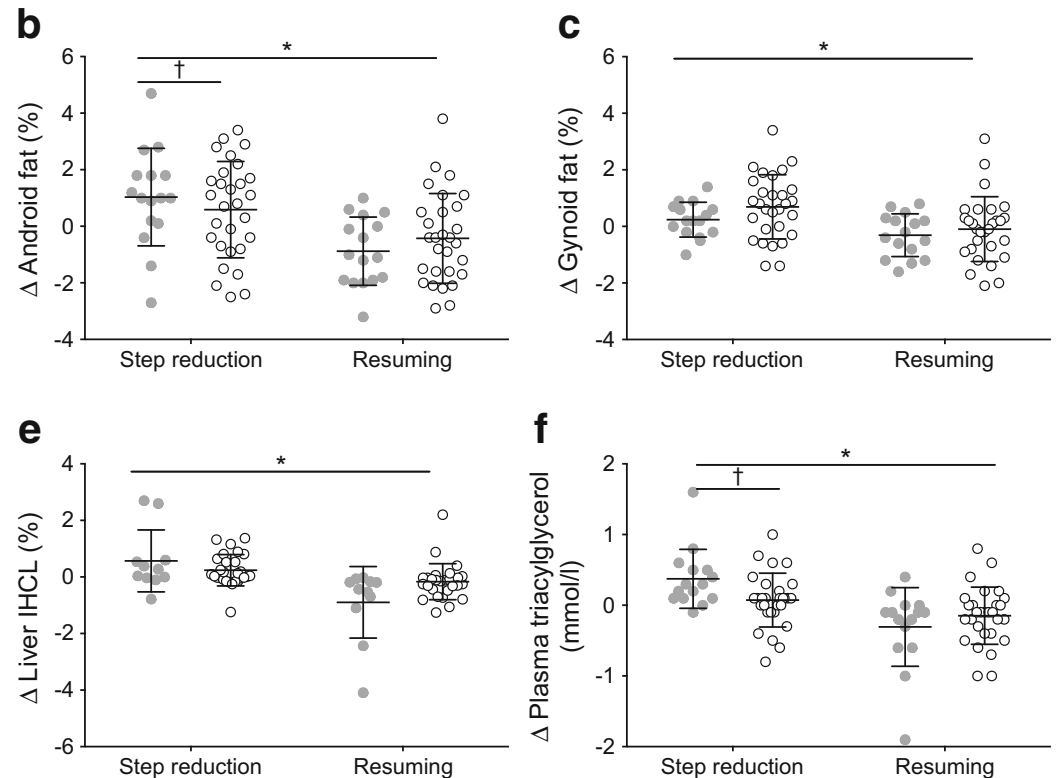

IHCL; and (f) plasma triacylglycerol. Data are presented as mean \pm SD. Grey circles, FDR+ve; white circles, FDR-ve. ${ }^{*} p<0.05$ main effect of time; ${ }^{\dagger} p<0.05$ between groups 
found, with FDR+ve individuals accumulating $1.5 \%$ more android fat $(0.4,2.6 ; p=0.008)$ following step reduction.

Liver and skeletal muscle fat Following the period of reduced activity, IHCL (liver fat) increased significantly by $0.7 \%(95 \%$ CI $0.2,1.2 ; p=0.001)$. Changes in IMCL (skeletal muscle fat) did not reach statistical significance $(p=0.094)$.

\section{Cardiorespiratory fitness}

The period of reduced physical activity significantly lowered cardiorespiratory fitness across the study population. This was the case whichever way fitness was expressed (absolute, relative to body weight or lean body mass): $\dot{\mathrm{VO}}_{2}$ by $0.3 \mathrm{l} / \mathrm{min}$ $(95 \%$ CI $0.5,1.0 ; p=0.002), \dot{V O}_{2 \text { peak }}$ per $\mathrm{kg}$ body mass by
$2.2 \mathrm{ml} \mathrm{min}^{-1} \mathrm{~kg}^{-1}(0.9,3.6 ; p=0.002)$ and $\dot{\mathrm{V}} \mathrm{O}_{2 \text { peak }}$ per $\mathrm{kg}$

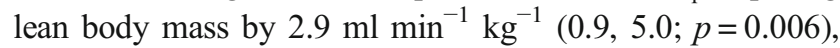
with no between-group differences for any of these measures.

\section{Return to normal activity}

All clinical, biochemical, body composition and cardiorespiratory fitness measures returned to baseline on resumption of habitual physical activity (Table 2).

\section{Within-group comparisons}

Several within-group responses were different in terms of reaching statistical significance. All measures of cardiorespiratory fitness (absolute, relative to body weight and relative to

Table 2 Change in variables for FDR+ve and FDR-ve individuals on step reduction and resumption of activity

\begin{tabular}{|c|c|c|c|c|c|c|c|}
\hline \multirow[t]{2}{*}{ Variable } & \multicolumn{2}{|l|}{ FDR+ve } & \multicolumn{2}{|l|}{ FDR-ve } & \multicolumn{2}{|c|}{ Between-group difference } & \multirow{2}{*}{$\begin{array}{l}p \text { value } \\
\text { Group [Time] }\end{array}$} \\
\hline & $\begin{array}{l}\Delta \text { Step } \\
\text { reduction }\end{array}$ & $\begin{array}{l}\Delta \text { Resuming } \\
\text { activity }\end{array}$ & $\begin{array}{l}\Delta \text { Step } \\
\text { reduction }\end{array}$ & $\begin{array}{l}\Delta \text { Resuming } \\
\text { activity }\end{array}$ & Step reduction & Resuming & \\
\hline \multicolumn{8}{|l|}{ Clinical characteristics } \\
\hline Body mass (kg) & $-0.1 \pm 1.0$ & $-0.1 \pm 1.2$ & $0.1 \pm 1.0$ & $0.3 \pm 1.2$ & $-0.2(-0.8,0.5)$ & $-0.4(-1.2,0.4)$ & $0.241[0.611]$ \\
\hline BMI $\left(\mathrm{kg} / \mathrm{m}^{2}\right)$ & $0 \pm 0.3$ & $0 \pm 0.4$ & $0 \pm 0.3$ & $0 \pm 0.4$ & $0(-0.3,0.2)$ & $0(-0.4,0.2)$ & $0.369[0.553]$ \\
\hline Waist circumference $(\mathrm{cm})^{\mathrm{a}}$ & $0.6 \pm 1.0$ & $-0.3 \pm 0.9$ & $0.7 \pm 1.0$ & $-0.4 \pm 0.8$ & $-0.1(-0.8,0.6)$ & $0.1(-0.5,0.7)$ & $0.934[<0.005]^{*}$ \\
\hline Hip circumference $(\mathrm{cm})^{\mathrm{a}}$ & $0.3 \pm 0.5$ & $-0.3 \pm 0.6$ & $0.1 \pm 0.5$ & $-0.1 \pm 0.6$ & $0.2(-0.2,0.5)$ & $-0.2(-0.7,0.2)$ & $0.670[<0.005]^{*}$ \\
\hline $\mathrm{SBP}(\mathrm{mmHg})$ & $-1 \pm 9$ & $-3 \pm 8$ & $2 \pm 8$ & $-4 \pm 8$ & $-2(-8,4)$ & $1(-4,7)$ & $0.654[0.037]^{*}$ \\
\hline DBP (mmHg) & $-1 \pm 8$ & $-2 \pm 9$ & $-1 \pm 8$ & $-1 \pm 8$ & $1(-5,6)$ & $-1(-7,5)$ & $0.846[0.982]$ \\
\hline \multicolumn{8}{|l|}{ Glucose metabolism } \\
\hline Fasting glucose (mmol/l) & $-0.1 \pm 0.5$ & $0.1 \pm 0.4$ & $-0.1 \pm 0.5$ & $-0.1 \pm 0.4$ & $0.1(-0.3,0.3)$ & $0.2(-0.1,0.5)$ & $0.171[0.294]$ \\
\hline Fasting insulin $(\mathrm{pmol} / \mathrm{l})^{\mathrm{a}}$ & $34 \pm 9$ & $-35 \pm 11$ & $17 \pm 8$ & $-11 \pm 11$ & $18(-24,59)$ & $-25(-79,30)$ & $0.669[0.016]^{*}$ \\
\hline HOMA-IR ${ }^{\mathrm{a}}$ & $1.1 \pm 2.1$ & $-1.1 \pm 2.6$ & $0.4 \pm 2.1$ & $-0.4 \pm 2.6$ & $0.7(-0.7,2.1)$ & $-0.7(-2.5,1.0)$ & $0.911[0.027]^{*}$ \\
\hline Whole-body IS ${ }^{\mathrm{b}}$ & $-0.7 \pm 1.2$ & $0.3 \pm 2.3$ & $-0.9 \pm 1.2$ & $1.3 \pm 2.2$ & $0.1(-0.7,1.0)$ & $-1.1(-2.7,0.5)$ & $0.254[<0.005]^{*}$ \\
\hline \multicolumn{8}{|l|}{ Lipid profile } \\
\hline Cholesterol (mmol/l) & $0.2 \pm 0.8$ & $-0.2 \pm 0.9$ & $0.2 \pm 0.8$ & $-0.3 \pm 0.8$ & $-0.1(-0.6,0.4)$ & $0.9(-0.5,0.7)$ & $0.962[0.041]^{*}$ \\
\hline HDL-cholesterol (mmol/l) & $-0.1 \pm 0.3$ & $0 \pm 0.4$ & $0 \pm 0.3$ & $0 \pm 0.4$ & $0(-0.2,0.2)$ & $0(-0.3,0.2)$ & $0.495[0.641]$ \\
\hline LDL-cholesterol (mmol/l) & $0.8 \pm 0.5$ & $-0.1 \pm 0.6$ & $1.2 \pm 0.5$ & $-0.2 \pm 0.5$ & $-0.2(-0.5,0.2)$ & $0.2(-0.2,0.5)$ & $0.930[0.013]^{*}$ \\
\hline \multicolumn{8}{|l|}{ Body composition } \\
\hline Total lean mass (kg) & $-0.6 \pm 0.9$ & $0.4 \pm 1.2$ & $-0.1 \pm 0.9$ & $0.4 \pm 1.1$ & $-0.4(-1.0,0.2)$ & $0.2(-0.6,1.0)$ & $0.598[0.005]^{*}$ \\
\hline Leg lean mass (kg) & $-0.1 \pm 0.4$ & $0.2 \pm 0.5$ & $-0.2 \pm 0.4$ & $0.2 \pm 0.5$ & $0.2(-0.1,0.4)$ & $-0.1(-0.4,0.3)$ & $0.589[0.004]^{*}$ \\
\hline Arm lean mass $(\mathrm{kg})$ & $0.1 \pm 0.2$ & $0.1 \pm 0.2$ & $-0.1 \pm 0.2$ & $0.1 \pm 0.2$ & $0.1(-0.1,0.2)$ & $0.1(-0.1,0.2)$ & $0.607[0.502]$ \\
\hline \multicolumn{8}{|l|}{ Cardiorespiratory fitness } \\
\hline$\dot{\mathrm{V}} \mathrm{O}_{2}(1 / \mathrm{min})$ & $-0.2 \pm 0.3$ & $0.3 \pm 0.4$ & $-0.1 \pm 0.3$ & $0.1 \pm 0.4$ & $-0.1(-0.3,0,1)$ & $0.2(-0.1,0.5)$ & $0.376[0.002]^{*}$ \\
\hline$\dot{\mathrm{V}} \mathrm{O}_{2 \text { peak }}\left(\mathrm{ml} \mathrm{min}{ }^{-1} \mathrm{~kg}^{-1}\right)$ & $-3.0 \pm 4.8$ & $3.6 \pm 5.6$ & $-1.4 \pm 4.6$ & $0.9 \pm 5.5$ & $-1.6(-4.8,1.6)$ & $2.7(-1.1,6.7)$ & $0.370[0.002]^{*}$ \\
\hline$\dot{\mathrm{VO}}_{2 \text { peak }}$ lean $\left(\mathrm{ml} \mathrm{min} \mathrm{mg}^{-1} \mathrm{~kg}^{-1}\right)$ & $-4.0 \pm 7.3$ & $4.9 \pm 8.5$ & $-1.9 \pm 6.9$ & $1.1 \pm 8.1$ & $-2.2(-7.1,2.7)$ & $3.9(-1.8,9.6)$ & $0.394[0.006]^{*}$ \\
\hline
\end{tabular}

Data shown are: mean change $\pm \mathrm{SD}$; between-group difference $(95 \% \mathrm{CI})$; and $p$ values for main group difference [pooled effect of time]. Values are presented to the nearest accuracy of measurement; where values do not demonstrate a change, data are presented with one decimal place; ' 0 ' is not absolute 0 but values $0 \pm 0.05$

${ }^{\text {a }}$ Variables analysed following logarithmic transformation

${ }^{\mathrm{b}}$ Matsuda index

IS, insulin sensitivity 
lean body) were significant in FDR+ve but not FDR-ve participants. For fasting insulin: FDR+ve $70 \pm 130 \mathrm{pmol} / 1$ $(p=0.046)$ vs FDR-ve $27 \pm 127 \mathrm{pmol} / 1(p=0.278)$. For NEFA AUC: FDR+ve $17 \pm 29 \mathrm{mmol} / 1 \times \min (p=0.017) \mathrm{vs}$ FDR-ve $2 \pm 30 \mathrm{mmol} / \mathrm{l} \times \min (p=0.715)$.

\section{Discussion}

The results of this study demonstrate that a short-term reduction in physical activity with increased sedentary behaviour, resulting in a decline in cardiorespiratory fitness, leads to unfavourable changes in body composition with reduced lower limb lean body mass, accretion of body fat, particularly centrally, and of liver fat. These changes are small, but nevertheless large enough to be clinically significant and thus to pose a serious health threat over a longer term [31]. The metabolic sequelae of these changes include whole-body insulin resistance and dyslipidaemia (increased triacylglycerol and LDL-cholesterol). Importantly, participants in the FDR+ve group demonstrated similar decompensation in whole-body insulin sensitivity when compared with those in the FDR-ve group. However, some differences were noted: greater rise in plasma triacylglycerol, more android fat deposition and reduced skeletal muscle insulin sensitivity. Although the changes observed in this short period were reversed on resumption of normal physical activity, the pattern of the changes provides mechanistic insight into how chronically increased sedentary behaviour contributes to development of the metabolic syndrome, type 2 diabetes, non-alcoholic fatty liver disease and, potentially, cardiovascular disease [32, 33].

Previous research has focused on increasing habitual physical activity or structured exercise, yet little is known about the consequences of decreasing habitual physical activity. We used validated measures of tissue-specific insulin sensitivity to demonstrate that inactivity resulted in decreased skeletal muscle insulin sensitivity. Skeletal muscle insulin sensitivity was significantly altered in both groups; notably, in FDR+ve participants, muscle insulin sensitivity did not return to baseline levels on resumption of habitual activity. While this may be an intrinsic defect, the FDR+ve individuals also had lower levels of vigorous activity on resumption of activity. As vigorous activity induces greater uptake of skeletal muscle glucose [34], this could have influenced this between-group difference.

We also observed increased adipose tissue insulin resistance with increased sedentary time, with lesser suppression of lipolysis and greater release of NEFA during the OGTT. We observed expansion of the adipose tissue mass and small but important increases in liver fat. This peripheral insulin resistance and accumulation of liver fat was accompanied by a rise in plasma triacylglycerol, LDL-cholesterol and an increase in $\mathrm{BP}$, all components of the metabolic syndrome (although no individuals developed it). These data are consistent with the hypothesis that increased sedentary time results in a reduced metabolic demand of skeletal muscle, leading to lower glucose uptake (by the development of peripheral insulin resistance) and repartitioning of energy substrates into storage in adipose tissue and in the liver by 'overspill', so that energy will be available when activity resumes [7]. This paradigm is supported by measurements of postprandial muscle and liver glycogen/lipid $\left({ }^{13} \mathrm{C} /{ }^{1} \mathrm{H}-\mathrm{MRS}\right)$ and de novo lipogenesis (deuterated water, ${ }^{2} \mathrm{H}_{2} \mathrm{O}$ ), which show that skeletal muscle insulin resistance promotes hepatic steatosis and hyperlipidaemia [5, 8]. Moreover, this process can be reversed with exercise [6]. We propose that increased sedentary time leads to central and hepatic fat accumulation, development of insulin resistance and emergence of components of the metabolic syndrome, including dyslipidaemia, by a similar mechanism (Fig. 6).

This step-reduction study somewhat corroborates previous reports regarding the effects on cardiorespiratory fitness and body composition [16, 17]. The effects of step reduction are amplified when combined with overfeeding [18], leading to undesirable metabolic changes, including impaired insulin sensitivity independent of changes in body composition. In our study, the detrimental changes were recovered on resumption of habitual activity. However, with overfeeding, body composition did not return to normal [18] and in older adults, glycaemic control and myofibrillar protein synthesis remained disrupted [20]. We believe our findings represent a significant advance for several reasons. Previous step-reduction studies have been limited in sample size, the largest comparable studies being in ten young men $[16,17]$; the present study is more representative of the general population, involving 45 individuals, both male and female, with a mean age of 36 years. We acknowledge their relatively high levels of habitual activity, despite being formally untrained. Complete objective monitoring of physical activity throughout ensured that the baseline criteria of $>10,000$ steps/day was met and likewise $\sim 1500$ steps/day (>80\% step reduction) during inactivity; habitual activity was monitored during the final 14 days, with no instruction or guidance; further, we characterised the time participants spent in domains of activity. Moreover, the participants were comprehensively phenotyped, including all measures of the metabolic syndrome, region-specific distribution and quantification of lean muscle and adipose tissue by DXA, and liver fat was quantified by ${ }^{1} \mathrm{H}-\mathrm{MRS}$, a highly sensitive non-invasive method [35].

The study is also the first to examine whether FDR+ve people are more susceptible to the detrimental effects of reduced physical activity than FDR-ve individuals. The findings do not suggest that FDR+ve individuals show greater adverse changes with decreased physical activity compared with FDR-ve individuals when we consider the effects on the primary outcome, whole-body insulin sensitivity. However, there were differences in a subset of measures, with 


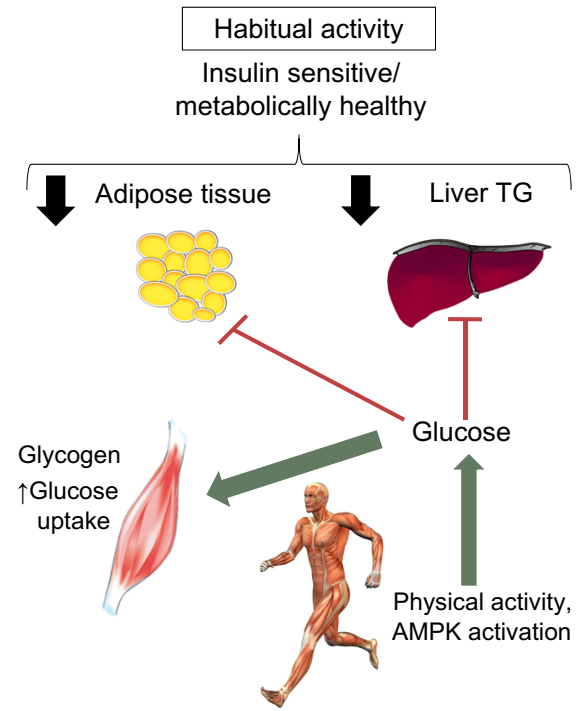

Fig. 6 Mechanisms of habitual activity vs chronic sedentary behaviour. A consequence of sedentary behaviour is lack of AMP-activated protein kinase (AMPK) activation and glucose uptake from skeletal muscle; this triggers insulin resistance and provides a substrate for de novo lipogenesis in adipose tissue and liver. Consequently, there is expansion of adipose tissue mass, an increase in NEFA flux and serum NEFA, intra-hepatic

greater increases in triacylglycerol and android fat following step reduction and a more marked change in cardiorespiratory fitness. These differences may be important, not only associated with an increased risk for future development of insulin resistance and type 2 diabetes, but also long term for cardiovascular disease and overall mortality [36]. The presence of good metabolic health in these relatively active individuals at baseline, the decline with increased sedentary time and restoration after resumption of habitual physical activity all, to some extent, validate current physical activity recommendations. The findings reinforce the importance of meeting the physical activity recommendations for all participants.

We acknowledge limitations to the study and its design. The target recruitment for FDR+ve participants was 20. The difficulty recruiting for this study was noteworthy. Physically active people were often reluctant to induce physiological harm, even for a brief period; subsequently, between-group comparisons may have been underpowered. We have presented evidence of within-group variation to highlight where degree of response is varied between the two groups, but recognise that this does not constitute a between-group difference. Furthermore, the practical intrusion of 'real life' (i.e. occupation, caring commitments) during the inactivity phase also explains why not all individuals could precisely reduce to 1500 steps/day.

We note the lack of a control group: an additional group, comprising participants who continue their habitual physical activity and having the same serial measurements, would have provided useful insight. Additionally, the gold standard measure of insulin sensitivity is the hyperinsulinaemic-

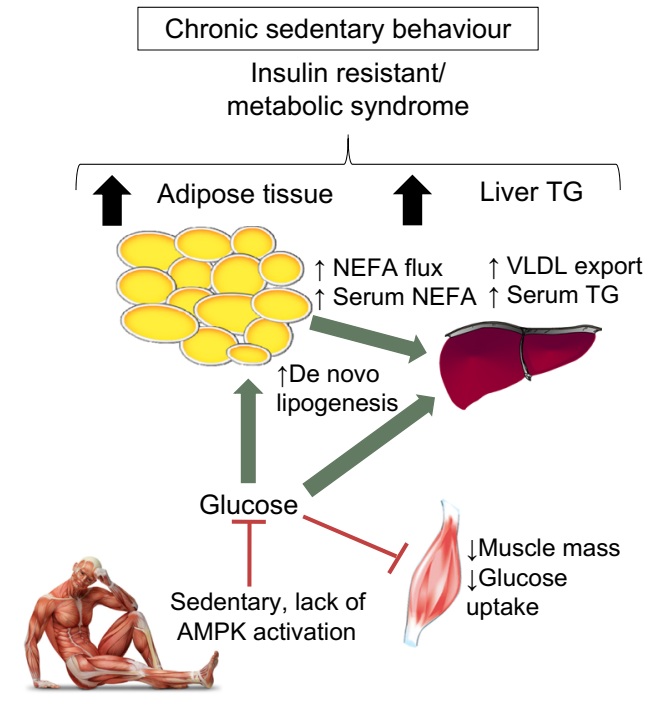

lipid accumulation and increased lipid exports as VLDL triacylglycerol particles and serum triacylglycerol with systemic insulin resistance. On the contrary, being habitually active promotes AMPK activation and uptake of glucose in skeletal muscle; insulin sensitivity is therefore preserved and less glucose is diverted to metabolically unfavourable depots. TG, triacylglycerol

euglycaemic clamp. Owing to the participant burden of conducting serial clamps, we opted to assess whole-body insulin sensitivity from an OGTT using the Matsuda index, which has been shown to correlate with hyperinsulinaemiceuglycaemic clamp [26]. Calculations of hepatic insulin resistance and skeletal muscle insulin sensitivity have also been validated [27]. The indices derived from OGTT are valid, repeatable and easily assessable measures of insulin sensitivity, which is advantageous for direct comparison with followup studies. Future studies may wish to incorporate low- and high-dose hyperinsulinaemic-euglycaemic clamps to measure precisely hepatic and skeletal muscle insulin sensitivity and consider dynamic measurements of de novo lipogenesis and of VLDL triacylglycerol kinetics to determine effects on liver fat and lipoprotein metabolism. These data provide a good rationale to determine the molecular and tissue-specific adaptations in skeletal muscle and subcutaneous adipose tissue in response to short-term physical inactivity.

In summary, by taking untrained individuals with a habitually active lifestyle (>10,000 steps/day) and drastically reducing their step count, this study provides direct evidence of a number of unfavourable adaptations to body composition and cardiometabolic risks with increased sedentary behaviour. These changes are reversed with resumption of habitual activity. The data suggest a mechanistic framework for understanding the deleterious cardiometabolic adaptations that occur with chronic physical inactivity and sedentary behaviour. Furthermore, both FDR+ve and FDR-ve individuals are susceptible to the risks of increased sedentary behaviour. The study findings reinforce the health benefits of meeting 
physical activity recommendations and emphasise the importance of reducing daily sedentary time.

Acknowledgements We thank A. Irwin (Obesity and Endocrinology, University Hospital Aintree) for clinical assistance and V. Adams for radiographic expertise at LiMRIC.

Data availability The datasets generated and analysed during the current study are available from the corresponding author on reasonable request.

Funding This work was supported by Diabetes UK (grant number 13/ 0004719), with additional funding support from the MRC-Arthritis Research UK Centre for Integrated research into Musculoskeletal Ageing (CIMA), Institute of Ageing and Chronic Disease, University of Liverpool.

Duality of interest The authors declare that there is no duality of interest associated with this manuscript.

Contribution statement DJC, GJK and JPHW conceived the study or parts of the study. KABD, VSS, JAN and DJC generated the data. GJK analysed the MRS data. KLM analysed the nutritional data. JCGH and JAH acquired DXA data. KABD and AT statistically analysed and interpreted the data. All authors participated in preparation of the manuscript and approved the final version for publication. KBD is the guarantor of this work.

Open Access This article is distributed under the terms of the Creative Commons Attribution 4.0 International License (http:// creativecommons.org/licenses/by/4.0/), which permits unrestricted use, distribution, and reproduction in any medium, provided you give appropriate credit to the original author(s) and the source, provide a link to the Creative Commons license, and indicate if changes were made.

\section{References}

1. Lee IM, Shiroma EJ, Lobelo F, Puska P, Blair SN, Katzmarzyk PT (2012) Effect of physical inactivity on major non-communicable diseases worldwide: an analysis of burden of disease and life expectancy. Lancet 380:219-229

2. Henson J, Yates T, Biddle SJ et al (2013) Associations of objectively measured sedentary behaviour and physical activity with markers of cardiometabolic health. Diabetologia 56:1012-1020

3. Smith AD, Crippa A, Woodcock J, Brage S (2016) Physical activity and incident type 2 diabetes mellitus: a systematic review and doseresponse meta-analysis of prospective cohort studies. Diabetologia 59:2527-2545

4. Tremblay MS, Aubert S, Barnes JD et al (2017) Sedentary Behavior Research Network (SBRN) - Terminology Consensus Project process and outcome. Int J Behav Nutr Phys Act 14:75

5. Jornayvaz FR, Samuel VT, Shulman GI (2010) The role of muscle insulin resistance in the pathogenesis of atherogenic dyslipidemia and nonalcoholic fatty liver disease associated with the metabolic syndrome. Annu Rev Nutr 30:273-290

6. Rabol R, Petersen KF, Dufour S, Flannery C, Shulman GI (2011) Reversal of muscle insulin resistance with exercise reduces postprandial hepatic de novo lipogenesis in insulin resistant individuals. Proc Natl Acad Sci U S A 108:13705-13709

7. Rector RS, Thyfault JP (2011) Does physical inactivity cause nonalcoholic fatty liver disease? J Appl Physiol 111:1828-1835
8. Petersen KF, Dufour S, Savage DB et al (2007) The role of skeletal muscle insulin resistance in the pathogenesis of the metabolic syndrome. Proc Natl Acad Sci 104:12587-12594

9. DeFronzo RA, Tripathy D (2009) Skeletal muscle insulin resistance is the primary defect in type 2 diabetes. Diabetes Care 32:S157S163

10. Tan CY, Vidal-Puig A (2008) Adipose tissue expandability: the metabolic problems of obesity may arise from the inability to become more obese. Biochem Soc Trans: 935-940

11. Alibegovic AC, Sonne MP, Hojbjerre L et al (2010) Insulin resistance induced by physical inactivity is associated with multiple transcriptional changes in skeletal muscle in young men. Am J Phys Endocrinol Metab 299:E752-E763

12. Abadi A, Glover EI, Isfort RJ, et al. (2009) Limb immobilization induces a coordinate down-regulation of mitochondrial and other metabolic pathways in men and women. PLoS One 4:e6518

13. King DS, Dalsky GP, Clutter WE et al (1988) Effects of lack of exercise on insulin secretion and action in trained subjects. Am J Physiol Endocrinol Metab 17:E537

14. Church TS, Thomas DM, Tudor-Locke C et al (2011) Trends over 5 decades in U.S. occupation-related physical activity and their associations with obesity. PLoS One 6:e19657

15. Althoff T, Sosic R, Hicks JL, King AC, Delp SL, Leskovec J (2017) Large-scale physical activity data reveal worldwide activity inequality. Nature 547:336-339

16. Krogh-Madsen R, Thyfault JP, Broholm C et al (2010) A 2-wk reduction of ambulatory activity attenuates peripheral insulin sensitivity. J Appl Physiol 108:1034-1040

17. Olsen RH, Krogh-Madsen R, Thomsen C et al (2008) Metabolic responses to reduced daily steps in healthy nonexercising men. JAMA 299:1261-1263

18. Knudsen SH, Hansen LS, Pedersen M et al (2012) Changes in insulin sensitivity precede changes in body composition during 14 days of step reduction combined with overfeeding in healthy young men. J Appl Physiol 113:7-15

19. Breen L, Stokes KA, Churchward-Venne TA et al (2013) Two weeks of reduced activity decreases leg lean mass and induces "anabolic resistance" of myofibrillar protein synthesis in healthy elderly. J Clin Endocrinol Metab 98:2604-2612

20. McGlory C, von Allmen MT, Stokes T et al (2017) Failed recovery of glycemic control and myofibrillar protein synthesis with two weeks of physical inactivity in overweight, pre-diabetic older adults. J Gerontol A Biol Sci Med Sci. https://doi.org/10.1093/gerona/glx203

21. Meigs JB, Cupples LA, Wilson PWF (2000) Parental transmission of type 2 diabetes: the Framingham Offspring Study. Diabetes 49: 2201-2207

22. Hu FB, Sigal RJ, Rich-Edwards JW et al (1999) Walking compared with vigorous physical activity and risk of type 2 diabetes in women: a prospective study. JAMA 282:1433-1439

23. Celis-Morales CA, Ghouri N, Bailey ME, Sattar N, Gill JM (2013) Should physical activity recommendations be ethnicity-specific? Evidence from a cross-sectional study of South Asian and European men. PLoS One 8:e82568

24. Matthews DR, Hosker JP, Rudenski AS, Naylor BA, Treacher DF, Turner RC (1985) Homeostasis model assessment: insulin resistance and beta-cell function from fasting plasma glucose and insulin concentrations in man. Diabetologia 28:412-419

25. Gutch M, Kumar S, Razi SM, Gupta KK, Gupta A (2015) Assessment of insulin sensitivity/resistance. Indian J Endocrinol Metab 19:160-164

26. Matsuda M, DeFronzo RA (1999) Insulin sensitivity indices obtained from oral glucose tolerance testing: comparison with the euglycemic insulin clamp. Diabetes Care 22:1462-1470

27. Abdul-Ghani MA, Matsuda M, Balas B, DeFronzo RA (2007) Muscle and liver insulin resistance indexes derived from the oral glucose tolerance test. Diabetes Care 30:89-94 
28. Cuthbertson DJ, Shojaee-moradie F, Sprung VS et al (2016) Dissociation between exercise-induced reduction in liver fat and changes in hepatic and peripheral glucose homeostasis in obese patients with Non-Alcoholic Fatty Liver Disease. Clin Sci 130: 93-104

29. Cuthbertson DJ, Irwin A, Gardner CJ et al (2012) Improved glycaemia correlates with liver fat reduction in obese, type 2 diabetes, patients given glucagon-like peptide-1 (GLP-1) receptor agonists. PLoS One 7:e50117

30. Jones H, Sprung VS, Pugh CJ et al (2012) Polycystic ovary syndrome with hyperandrogenism is characterized by an increased risk of hepatic steatosis compared to nonhyperandrogenic PCOS phenotypes and healthy controls, independent of obesity and insulin resistance. J Clin Endocrinol Metab 97:3709-3716

31. Thyfault JP, Krogh-Madsen R (2011) Metabolic disruptions induced by reduced ambulatory activity in free-living humans. J Appl Physiol 111:1218-1224

32. Wilmot EG, Edwardson CL, Achana FA et al (2012) Sedentary time in adults and the association with diabetes, cardiovascular disease and death: systematic review and meta-analysis. Diabetologia 55: 2895-2905

33. Hallsworth K, Thoma C, Moore S et al (2015) Non-alcoholic fatty liver disease is associated with higher levels of measured sedentary behaviour and lower levels of physical activity than matched healthy controls. Front Gastroenterol 6:44-51

34. Cassidy S, Thoma C, Houghton D, Trenell M (2017) High-intensity interval training: a review of its impact on glucose control and cardiometabolic health. Diabetologia 60:7

35. Cuthbertson DJ, Weickert MO, Lythgoe D et al (2014) External validation of the fatty liver index and lipid accumulation product indices, using 1H-magnetic resonance spectroscopy, to identify hepatic steatosis in healthy controls and obese, insulin-resistant individuals. Eur J Endocrinol 171:561-569

36. Pinnick KE, Nicholson G, Manolopoulos KN et al (2014) Distinct developmental profile of lower-body adipose tissue defines resistance against obesity-associated metabolic complications. Diabetes 63:3785-3797 